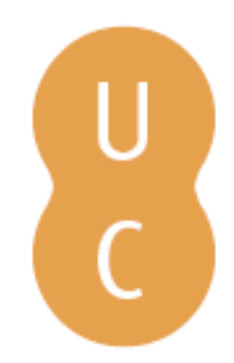

\title{
pommalina
}

\section{RPAS and nighttime wildfire fighting: the NITROFIREX PROJECT}

\author{
Autor(es): $\quad$ Bordallo, Luis M.; Burwitz, Alexander \\ Publicado por: Imprensa da Universidade de Coimbra \\ URL \\ persistente: URI:http://hdl.handle.net/10316.2/44586 \\ DOI: $\quad$ DOI:https://doi.org/10.14195/978-989-26-16-506_69
}

Accessed : $\quad$ 26-Apr-2023 03:39:07

A navegação consulta e descarregamento dos títulos inseridos nas Bibliotecas Digitais UC Digitalis, UC Pombalina e UC Impactum, pressupõem a aceitação plena e sem reservas dos Termos e Condições de Uso destas Bibliotecas Digitais, disponíveis em https://digitalis.uc.pt/pt-pt/termos.

Conforme exposto nos referidos Termos e Condições de Uso, o descarregamento de títulos de acesso restrito requer uma licença válida de autorização devendo o utilizador aceder ao(s) documento(s) a partir de um endereço de IP da instituição detentora da supramencionada licença.

Ao utilizador é apenas permitido o descarregamento para uso pessoal, pelo que o emprego do(s) título(s) descarregado(s) para outro fim, designadamente comercial, carece de autorização do respetivo autor ou editor da obra.

Na medida em que todas as obras da UC Digitalis se encontram protegidas pelo Código do Direito de Autor e Direitos Conexos e demais legislação aplicável, toda a cópia, parcial ou total, deste documento, nos casos em que é legalmente admitida, deverá conter ou fazer-se acompanhar por este aviso.

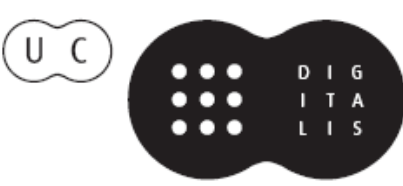




\section{ADVANCES IN}

\section{FOREST FIRE RESEARCH}

\section{8}

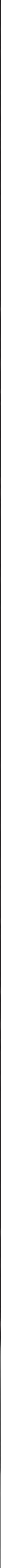




\title{
RPAS and nighttime wildfire fighting: The NITROFIREX PROJECT
}

\author{
Luis M. Bordallo ${ }^{1}$, Alexander Burwitz ${ }^{2}$

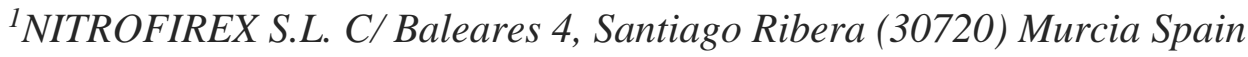 \\ \{luisbordallo@nitrofirex.com\} \\ ${ }^{2}$ NF Advanced Engineering C/Fraday, Campus Cantoblanco, 28049 Madrid \\ \{alexander.burwitz@nitrofirex.com\}
}

\begin{abstract}
The maturity of the technologies for the guidance and control of UASs allows proposing innovative operational options such as the ability to spray (a liquid) or spread (a powder) a significant amount of an agent of any sort at a pre-established point in the atmosphere. This is the case of NITROFIREX, an innovative project that integrates available technologies from the defence industry to achieve this operational capability. Of all possible applications the forest-fire fighting is where NITROFIREX places its highest priority. This is because of the ecological damage these fires bring forth, the cause social alarm they generate and the human and economic losses that take place whilst fighting them. NITROFIREX at last offers the long awaited nighttime fire fighting capability and also allows direct support to the ground crews in their relentless fight against forest fires.

The ability to transport large amount of payload in the minimum time to the area of operations is performed by heavy transport aircraft or helicopter (Launcher Aircraft L A) designed to do this at the most efficient economical way. What NITROFIREX does is to transport this payload from the transport aircraft / helicopter to the programmed release point. This is achieved by using unmanned Autonomous Gliders Containers, AGCs that are released through the rear ramp of the LAs. The AGCs fly autonomously to the programmed release point in the source of the fire realizing their contents with utmost precision and then returning to base for reuse. Once the AGG drops the extinguishing agent it performs its escape manoeuvre using its remaining speed and big weight loss to attain as much altitude as possible. Upon reaching the highest point it returns to its base of operations, empty now, so as to be reused as soon as possible. The base of operations is an airport close to the fire to which the NitroFirex system is moved when called for.

The amount of countries hit by forest fires is numerous. The heavy financial and human losses generate social unease and political concern. The impact on the environment incurs in a direct manner in harm to biodiversity and indirectly with the release of big amounts of carbon dioxide into the atmosphere. Paradoxically in the sector of aerial fire fighting no modern aeronautic technologies have been implemented up to now, especially if we compare it to all other sectors of aviation where the innovations have been really significant. Because of all that has been mentioned the NITROFIREX project raises the application of modern technology in the aviation sector with the goal to improve to improve the operative efficacy, the economical efficiency, the crews flaying safety and above all to offer night-time operation, which is the main shortcoming of current aerial means.
\end{abstract}

For further information see 3 min YOUTUBE video link: https://www.youtube.com/watch?v=MTOjTWSHR64\&feature=youtu.be

Keywords: Drones, night-time, aerial, forest, fire fighting, AGC's, launcher aircraft

\section{Introduction}

It may be the controversial climate change or perhaps human pressure on the natural environment but the fact is that, year after year, alarming reports of devastating forest fires monopolize the media. During all he last summers we saw how catastrophic fires razed through the U.S.A., Portugal, Canada, Spain Indonesia, Russia, Bolivia, Israel, India, Australia and Greece stood by helplessly before the devastation of their natural heritage. In the coming years, and this is unfortunately more than likely, we shall have to continue suffering from this modern plague that is ravaging our forests. 
In facing this bitter reality, it is necessary to ask whether political, economic and technical levels are contributing in finding solutions, or at least methods to efficiently avoid and relieve these disasters. Unfortunately, the answer is a very clear and definite negative.

According to estimates from the Intergovernmental Panel on Climate Change (IPCC), forest fires create between 14 to $20 \%$ of all $\mathrm{CO}_{2}$ projected into the atmosphere annually.

On the other hand, all the activity of commercial aviation worldwide causes only $2 \%$ of all the $\mathrm{CO}_{2}$ emission. For example, the European project CLEANSKY has a budget estimated at 1,600 millions of Euros in order to reduce this $2 \%$ to $1 \%$ by obtaining a higher efficiency of engines, the employment of biofuels, intelligent wings and the reduction of weight, etc. Paradoxically, very little technological effort is being put into research regarding the elimination or the reduction of the $14-20 \%$ emission of $\mathrm{CO}_{2}$ that results from wild fires and, above all, the lack of research into aerial fire extinction - the most versatile and effective method to fight fires.

In the face of the social alarm, political upheaval and vast economic losses engendered by these wildfires, why is it that so few technical resources are available to fight these fires with the greatest efficiency possible? Why, for example, having at our finger tips technology that literally allows us to place a guided bomb carrying 200 or 300 kilos of explosives and fired from a warplane some dozens of miles away through a window? (Figure 1) Why can't we use the same technology to drop, throughout the night, loads of 2,000 to 3,000 litres of water continuously over a burning forest?

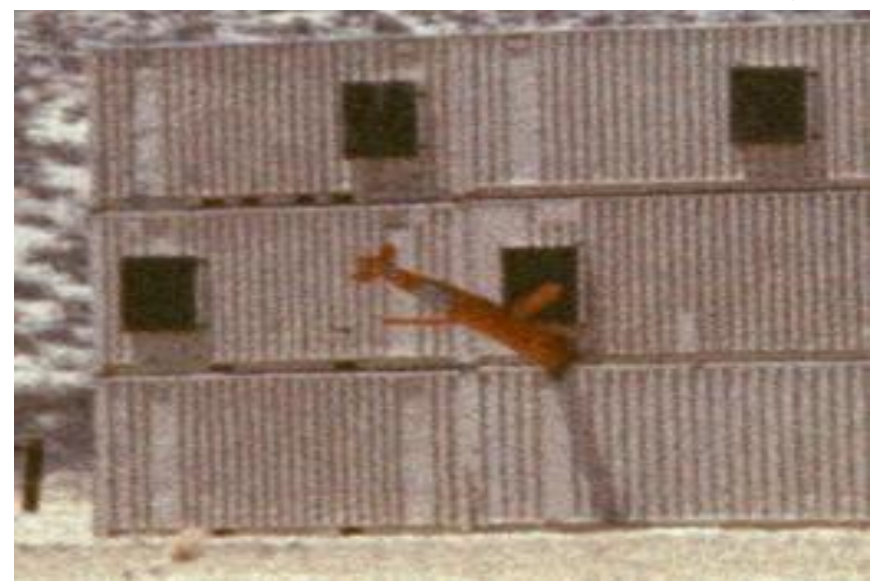

Figure 1 - Guided/guided bomb striking a target

Why is it that an aeronautical sector, which internationally moves thousands of millions of $\$ / €$, is still confined to using methods, techniques and procedures developed some 60 years ago in extreme high risk operations for their crews? Why not integrate available technology and develop the capacity to drop more fire extinguishing agents in less time, but above all, to be able to do so at night. Have we forgotten that the inability to fly at night is the greatest operative lack in present-day fire fighting?

\section{The NITROFIREX Concept}

The developing technologies in the control and guiding of RPAS allow for the development of innovative operational options, such as the possibility of 'spraying' (a liquid) or 'scattering' (a powdered solid) an important amount of extinguishing agent from a programmed point in the atmosphere.

This is the case of NITROFIREX, an innovative project that integrates the industrial technologies of the Defence Force in order to attain an operative capability that could be applied in the battle against wildfires, to combat against an atomic, chemical or biological emergency, to operate with meteorological phenomena (inducing rain, avoiding hail, dissipating fogs), to fight against plagues or to sow in remote or inaccessible regions and also the fumigation of drug plantations at night. 
Discarding all these possible applications, and due to the ecological harm caused, the social alarm generated as well as the human and economic losses that they bring forth, the project that NitroFirex is developing with maximum priority is the one to combat wildfires. For that very reason NitroFirex is concentrating on its night time operations as an indispensible and necessary complement to aerial means already in use during daytime. Heavy transport planes or helicopters will be responsible for moving great quantities of useful cargo (extinguishing agents in the case of wildfires) to the operative zone. These planes / helicopters are designed to transport at great speed big quantities of cargo at a cost per unit far lower to that of a smaller plane or helicopters.

This is the NitroFirex proposal: Launcher Aircraft (LAs), heavy cargo aircraft equipped with a rear ramp or medium/heavy helicopter (Figure 3 and 4), will be employed to transport the NitroFirex Airborne Glider Containers (AGCs) already containing around 2,500 litters of payload to the programmed drop zone (Figure 2).

The LA will then launch the AGCs from the rear ramp in a programmed sequence (Figure 3 ) or one by one hanged like a bucket-bamby from a helicopter (Figure 4). Once released, the AGCs will automatically homing onto their programmed target area within the drop zone and, with great accuracy, drop their load in the core of the fire. Once the drop of the fire-extinguishing agent on the fire has taken place, these containers return to base performing an "escape" manoeuvre from the danger zone by taking advantage of the great and sudden loss of weight as well as the extra speed.
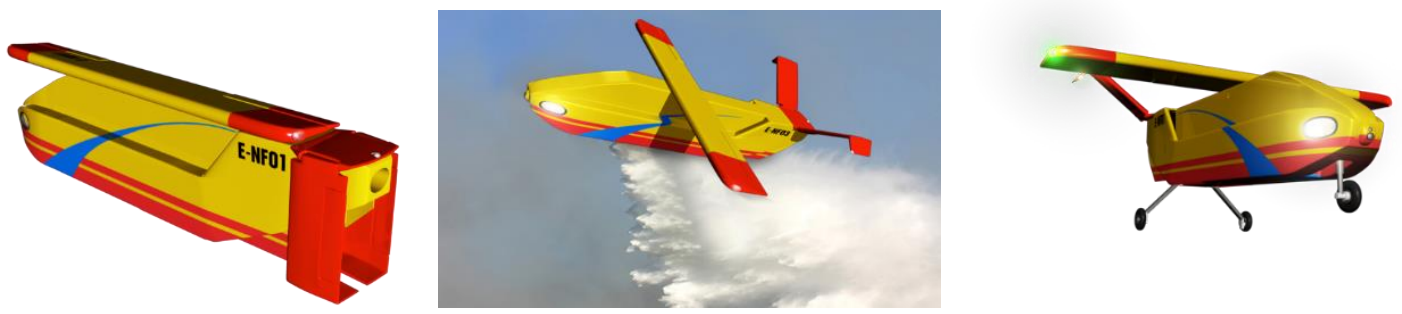

Figure 2 - NitroFirex AGC,s configurations (on board, flaying/dropping, landing or on ground)

Then the empty NitroFirex AGC begins its autonomous return to the operations base of the LA where it can be swiftly reused and loaded into the LA, thus beginning a constant turnaround operation until sunrise.

\section{The NITROFIREX Project}

Although, as we have seen in the previous paragraph, the concept has wide applications, NitroFirex is, first and foremost, a completely innovative project focused on nighttime aerial wildfire fighting. The main element used is the AGC, launched at medium altitude (six to ten thousand feet), from the rear ramp of the cargo bay of a medium/heavy transport aircraft, (Figure 3) (such as the C-295, C-27J, C-130 Hercules, AN-12, KC-390, A400M, IL-76, C-17 or even aircraft with greater cargo capacity), or from any medium/heavy helicopter hanging like a bucket (Bamby) (Figure 4) (such as Eurocopter models H-225, H-215 H-175, Bell models B-412, B-214, B-212, or Sikorsky models S61, S65, S70 or the Kamov 32 between others), which perform as the LAs.

These containers, loaded with a fire-extinguishing agent, are capable of gliding in their initial phase and are equipped with a guidance system (satellite, inertial, infrared or even laser). They fly automatically into the fire zone and drop their load, in sequence and with great accuracy, on the targeted area over the flames (Figure 5). 


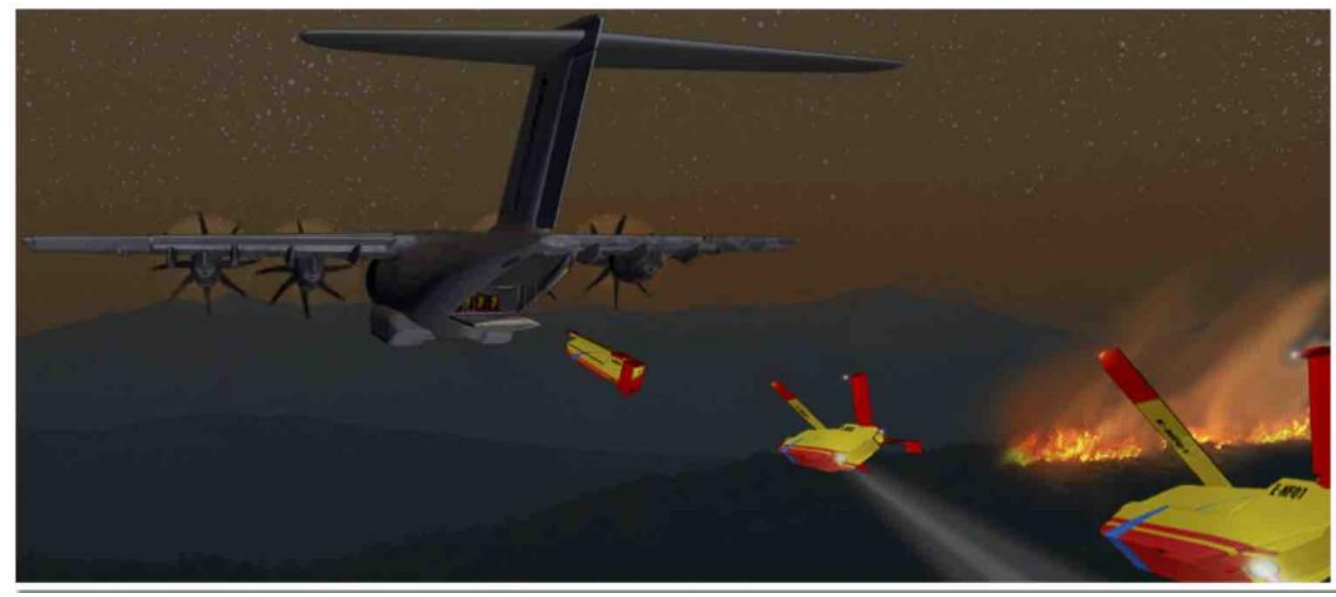

Figure 3 - Launching of AGSs from the LA (heavy cargo transport) at night

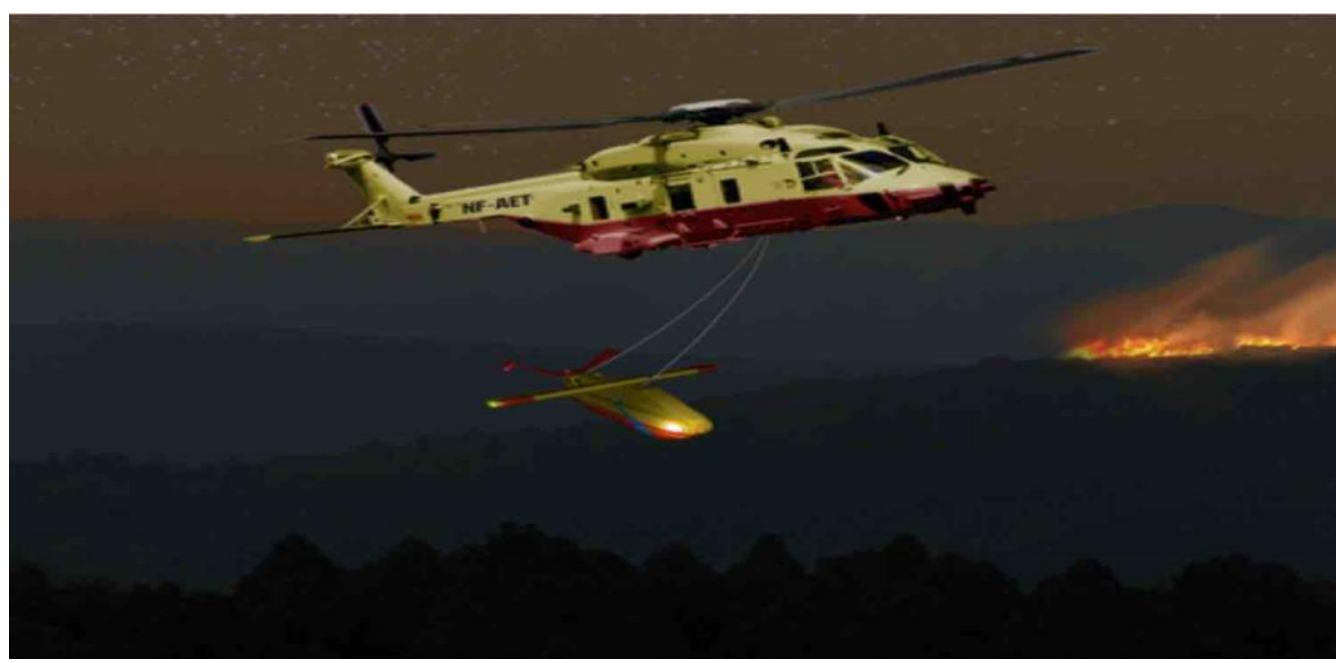

Figure 4 - Launching of AGSs from the LA (heavy cargo helicopter) at night

For safety, but also economic reasons, the AGCs are recoverable. Once the drop of fireextinguishing agent on the fire takes place, the AGCs perform an escape manoeuvre from the danger zone. Taking advantage of the great and sudden loss of weight as well as the surplus speed, the empty glider container is transformed, thanks to the previously activated small engine that propels it, into an RPAS and returns autonomously to the operation base of the LA where it can be swiftly reused. In its guided bomb role, the glider container flies no more than 90 seconds from the LA to its target over the fire.

When compared to a guided bomb, it carries a bigger payload and has more wing surface, but with an equal gliding and guide capacity. After concluding its 'escape' from the target area and until it lands at the LA.s operation base, it navigates at night as a RPAS at 500 feet above ground level and attains speeds of up to $70 \mathrm{Kts}$ (Figure 6).

By no means does NitroFirex want to substitute current aerial means whose efficiency in daytime operations has been demonstrated over decades. The truth is that NitroFirex aims to be their night-time counterpart in order to achieve H-24 aerial combat against wildfires (24 hour non-stop fighting) and to make use of, as the toiling ground crews well know, the better weather conditions that the night usually has to offer (less turbulence and wind, lower temperature and higher humidity). 


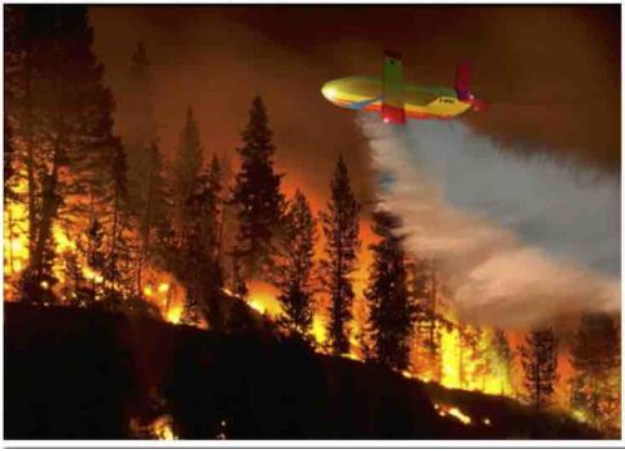

Figure 5 - AGCs dropping fire agents Extinguishing on the fire

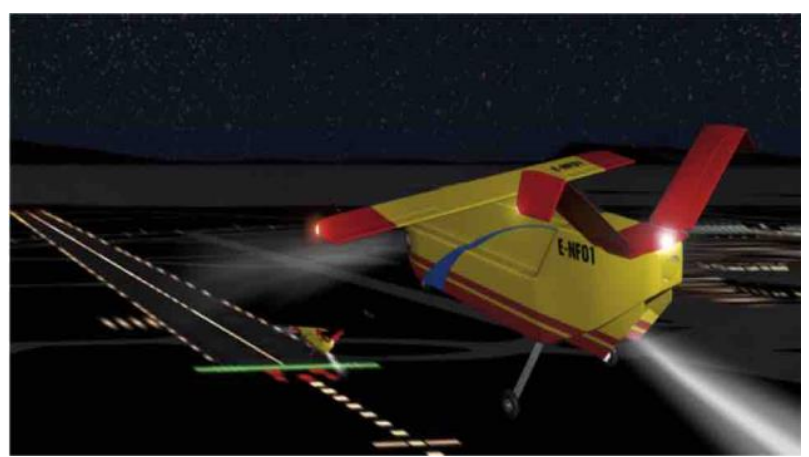

Figure6 - Coordinated autonomic return and Landing at the LA,s operation base

In the next Figures 7, 8 and 9, one can analyse these advantages from:

$1^{\circ}$ the operative point of view: litters launched per hour of the operation in function of the distance from the LA ops base to the forest fire.

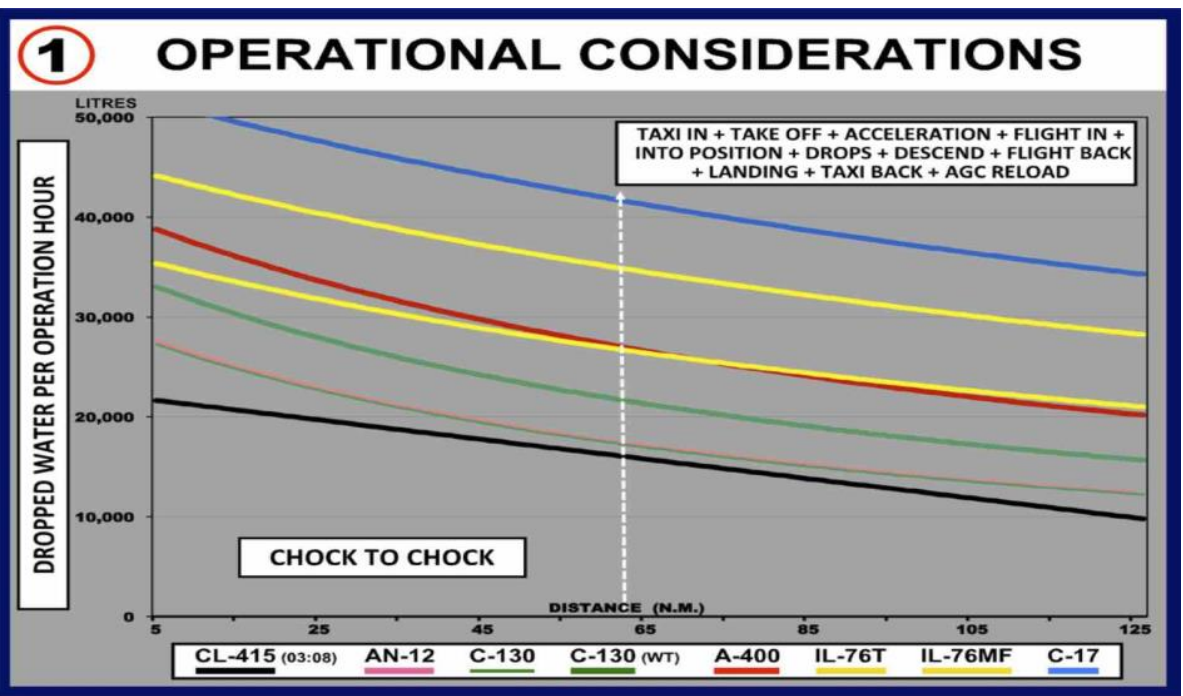

Figure7 - Dropped water per hour of operation

$2^{\circ}$ The economic point of view: litters launched per flight hour and the cost of the dropped litter in function of the distance from the LA ops base to the forest fire.

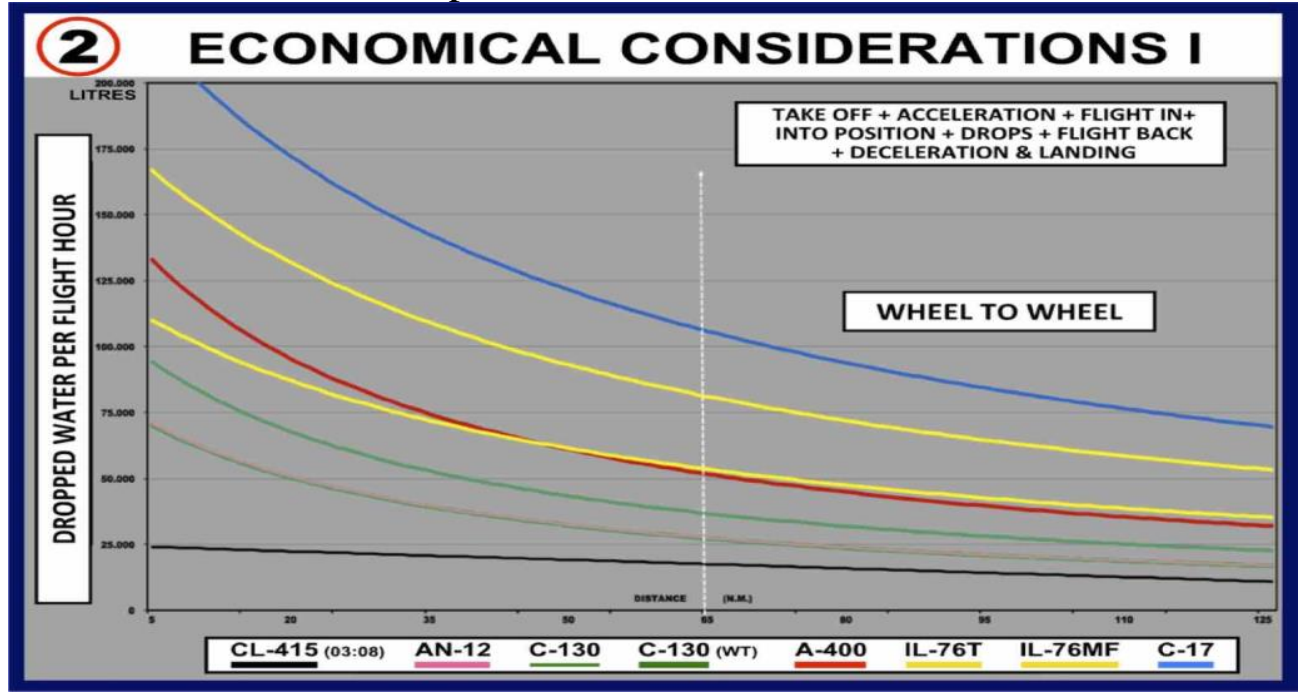

Figure 8 - Dropped water per flight hour. 


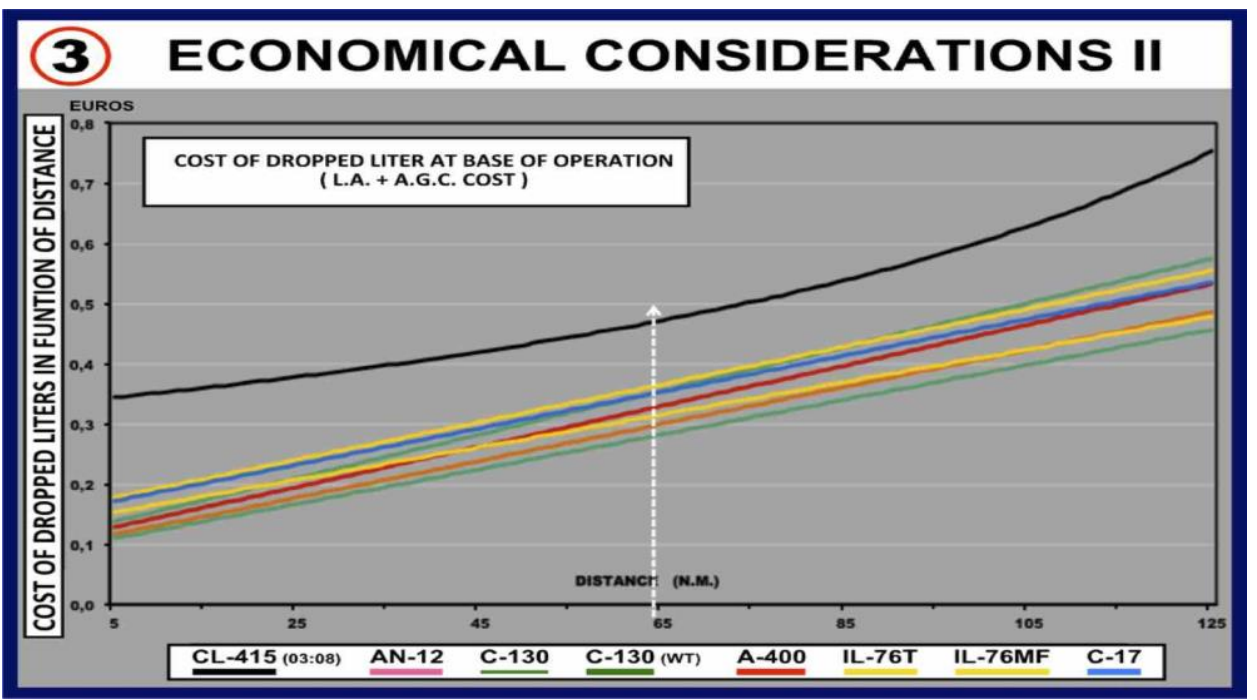

Figure 9: Cost of dropped water as a function of distance

\section{Operational Model}

Because of the great cargo capability and the increased deployment speed that the LAs offer, a new operational model will have to be put into use. This will include a regional operational base that could be situated in a strategic site in accordance to the operations area. Should a supranational operation come to be, the ideal base that would cover, for example, the Mediterranean Basin would be Marseille in France. Since the NitroFirex operation is nocturnal, we can assure that under normal conditions, at least half a day would be needed to detach the LA to any "available runway" in any country (Figure 10).

The AGCs are transported from the "regional operational base" to the "mission base" (airport, air base or aerodrome closest to the fire). Two sets of empty AGCs are stacked on two levels in a 'rack' or specifically designed shelving in the cargo hold of the LA (Figure 11).

Later, during the mission this 'rack' will be used for the fast turn-around (pre-flight check, fuelling, loading of extinguishing agent and re-stacking) of the AGCs returning from the fire zone. Once a wildfire alarm has been activated, the LA fly from their regional base to the detachment base, the airport closest to the fire, where the operation begins by downloading the rack of empty AGCs and the rest of the necessary equipment so as to proceed with the final preparation. The first set of AGCs (on the lower level of the 'rack') are filled with the extinguishing agent and are once again stacked in the LA leaving them ready for take off at dusk.

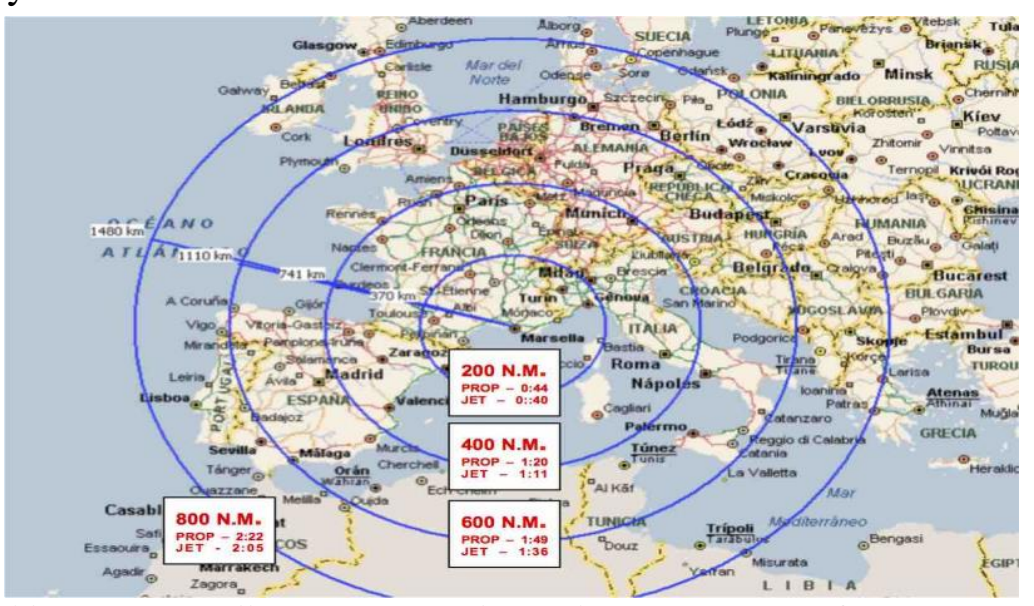

Figure 10 - Proposed base at Marseille in France in the Mediterranean Basin for a supranational operation. 


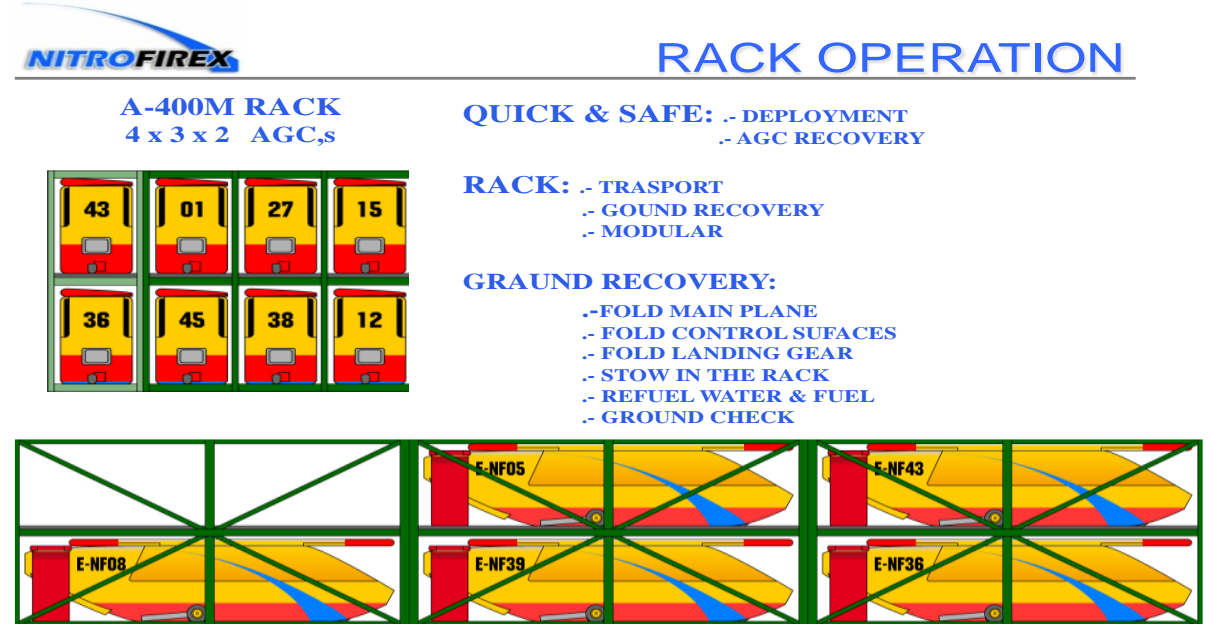

Figure 11 - Rack operations of the AGCs.

As night falls they fly to the fire zone and, coordinated by the ground teams who provide direct support, the LAs begins launching the AGCs in groups with a $90^{\circ}$ 'angle off' to the fire front, the goal being that at the moment of leaving the LA the AGCs make a $90^{\circ}$ turn, so that when several AGCs leave the LA they can form up in a "trail" formation and attack the fire.

The extinguishing agent is dropped over the area preselected by the fire management officer. In order to maximize the extinguishing effect the drops are overlapped. Once the first set of AGCs have left the LA, it returns to base to load the second set of AGCs so it can then return to the fire area in order to continue the attack on same fire or to attack more than one fire simultaneously. The AGCs autonomously return to mission-base after each drop. For example, one could consider an operation of an A-400 with a cargo capacity of 12 full AGCs.

Flying to the mission-base with a 'rack' holding 24 empty in each flight 12 containers filled with the extinguishing agent and rapidly returns to load the next 12 .

In the case of the A-400, the cargo load of each AGC would be 2,583 litres, which means that a single flight of an A-400 would be approximately equivalent to 6 drops of the Canadair CL-215/415. At a distance of $120 \mathrm{~km}(65 \mathrm{~nm})$ between the mission base and the fire zone an A-400 can perform 9 flights in one night dropping 12 AGCs with each flight.

According to operative analyses carried out by NitroFirex, and assuming the loading and stowage coefficients for the AGCs, one can establish that having one LA and its two sets of AGCs

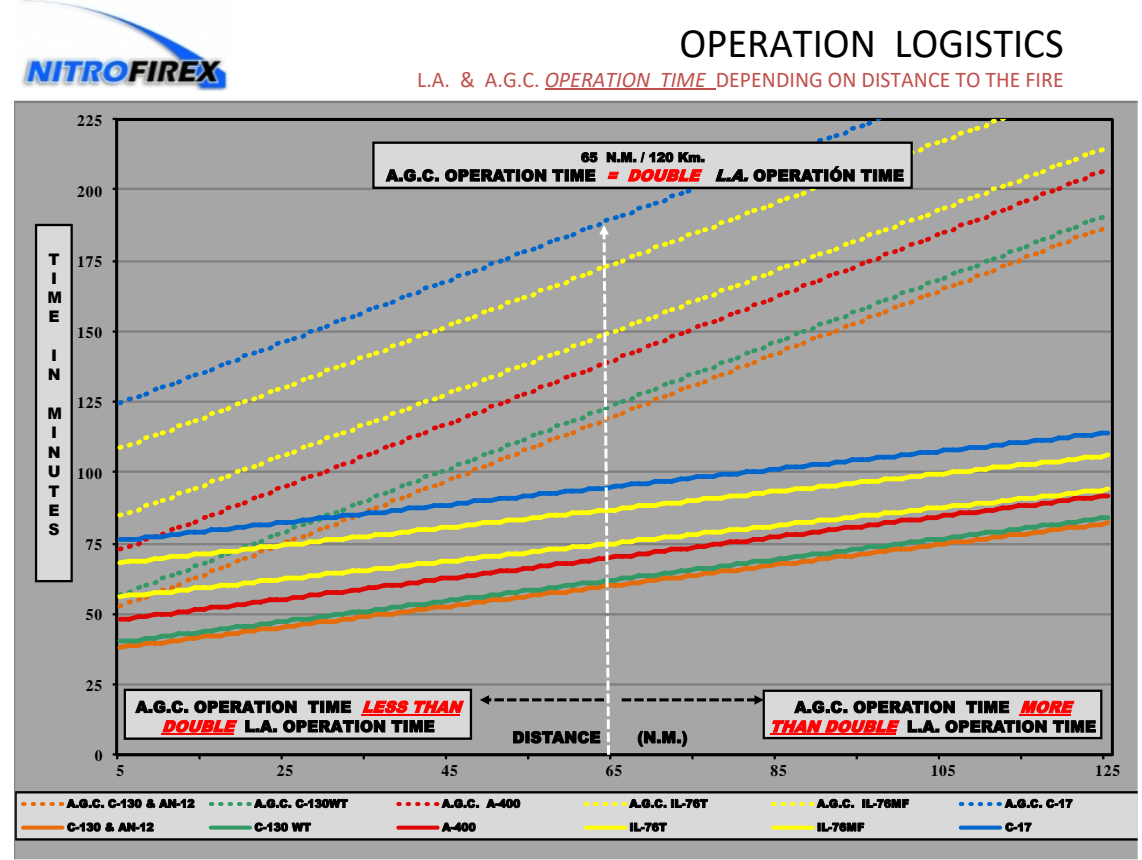

Figure 12 - NitroFirex operation logistics, Ops time LAs versus AGCs 
detached to a mission base within $120 \mathrm{~km}$ (65 N.M.), the operation over the fire zone would be nonstop.

The LA turn-around at mission base for loading the AGCs would ensure a relentless dropping of water over the intended targets (Figs. 12 and 13).

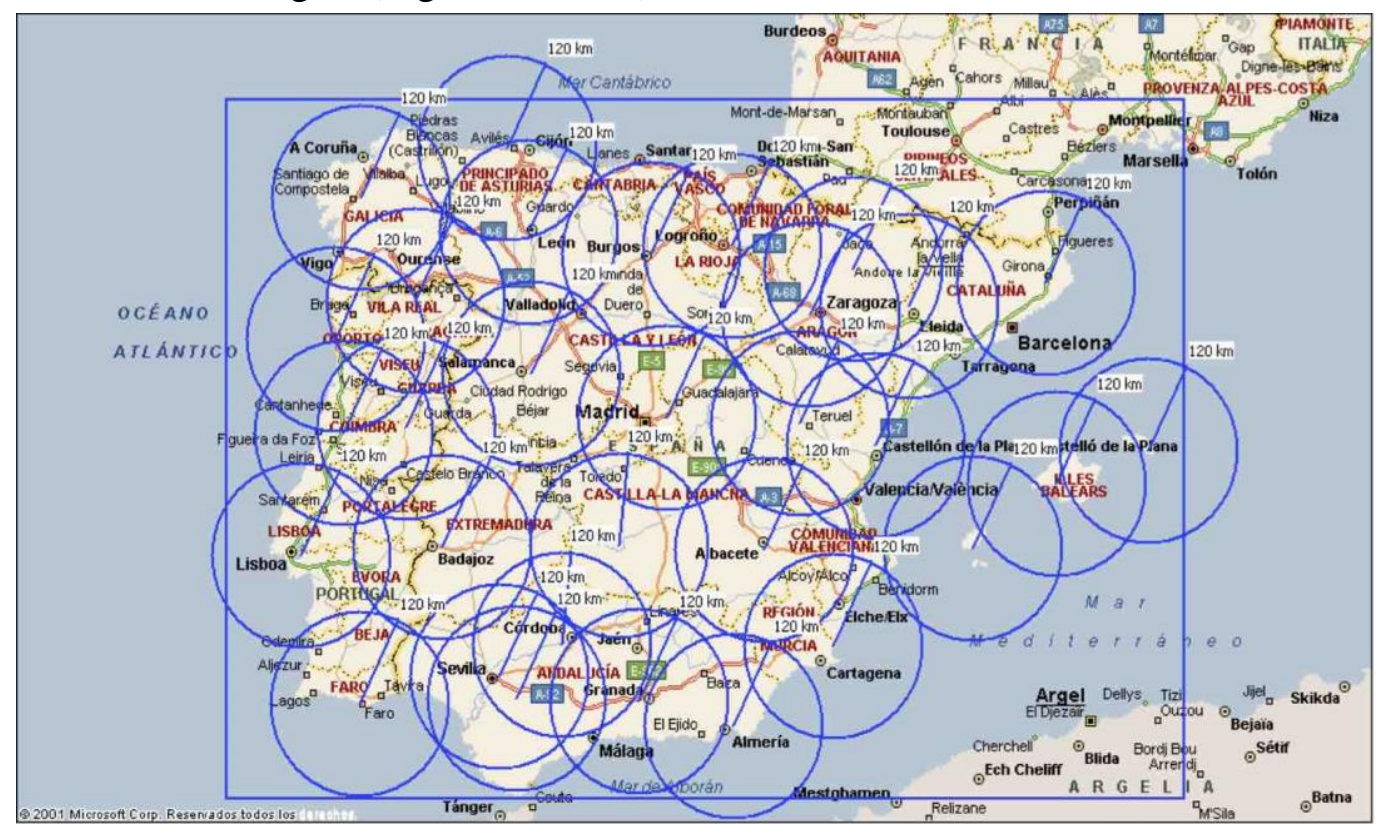

Figure 13 - NitroFirex mission analysis 65 N.M. airport radius Coordination and Safety

Those dedicated to aerial fire fighting know the importance of ground/air coordination to ensure an efficient and safe operation. With this objective in mind NitroFirex the implementation of new operative protocols and rules of communication with ground crews that are needed to adapt to the requirements of this project.

It should be the fire management officer who maintains radio contact with the LAs and the missionbase to coordinate the whole operation, principally the waiting points of the LAs as well as the approach routes and drop points of the AGCs.

At night it becomes very important that the ground crews can see the approach and the drop from the AGCs. For that reason, apart from the standard lights of all aerial vehicles (navigation, Beacon, strobe and logo lights), the NitroFirex are equipped with lights illuminating the fuselage as well as powerful headlamps. These headlamps are aimed forwards so that ground crews will be able to see them in the far distance and calculate the speed of approach to the drop point. Therefore, ground crews will be able to very clearly see the approach, the actual drop and its effect on the fire as well as the AGCs departure from the drop point.

In any type of aerial operation safety is of primordial importance at the time of planning, something to which NitroFirex is not indifferent. Consequently, the NitroFirex in their approach to the drop, as well as in the recovery phase to mission base, will have their flight parameters programmed and will accomplish them automatically and autonomously. Nonetheless, the safety concept of 'a man in a loop', in the case of having to abort the drop or reprogram the recuperation route, has been considered fundamental for the safety of the operation.

Therefore, during the approach phase, the NitroFirex will be capable of manually or automatically aborting their approach to the drop point, releasing their cargo at the abort point and then proceeding automatically into the escape and recovery phase. Should the flight trajectory deviate from the one established or an unexpected event occurs during the approach to the drop point and it becomes 
advisable not to continue, the abort can be manual, carried out by the fire management officer or by AGCs operators at LA or at mission-base. The NitroFirex AGC can automatically abort if its flight path does not match with what had been programmed or if it approaches the ground and/or a nondesired location.

In any case, the AGCs never reaches the ground filled with extinguishing agents, because if any thing deviates from what was programmed the cargo is immediately released and it then moves into the recovery phase.

On the other hand, the return route of the AGCs to mission base will be programmed for the night (they have all day to do it), at $500 \mathrm{ft}$ or less and over uninhabited areas. Should, by any chance, the AGCs engine have a flameout or any other malfunction, during the return it is equipped with a parachute and an airbag, which opens up automatically and that allows for a 'soft landing', minimizing any possible damage on ground to persons or goods.

\section{Technical Regulations for the Operation of RPAS}

Today, the great stumbling block in operating RPAS in purely civilian aerial operations is the regulations controlling the airspace where both manned and unmanned aircraft could operate safely and this regulation also has to ensure the safety of goods and persons on ground and his privacy. For promoting the development of such rules and regulations at European level the ESA (European Space Agency) established the operation of RPAS. Considering the broad range of operations and types of drones, it is proposed to establish 3 categories of operations and their associated regulatory regime: Open, Specific and Certified.

OPEN are those RPAS that basically operate in 'Visual Line of Sight' conditions, that is to say that at all moments there is visual contact between the vehicle and the operator. The operator's responsibility is to avoid any situation that could endanger any other aerial vehicle (manned or unmanned) or properties or persons on the ground and also is his responsibility to safeguard the citizen's privacy. The regulations of this category is responsibility of the different states of the European Union and the MTOW of the RPAS operating under the rules of this categories should be below $150 \mathrm{KG}$.

SPECIFIC is the category that "should be regulated in proportionate to the risk of the specific operation", this category initially has not MTOW limitations and his regulations are responsibility of UE concern agencies and at the same time of the different states of the European Union. The objective of this category is regulating for a "specific fly profile for a specific operations" ensuring that this profile does not affect fly or ground safety nor citizens privacy. Inside this category should be included what we can consider "state civil operations" like are SAR, disaster monitoring, border control, forest fire fighting, police, etc.

Finally the third category is the CERTIFIED that will be RPAS able of fly in the same operational environment (air space and endurance) that the manned aircrafts, therefore, Certified regulating for RPAS is more complex, entailing greater technical requirements that will be needed because of the new players involved. These players range from the RPAS operator to the air traffic controllers as well as the pilots of the manned aircraft.

The final operational achievements of the RPAS advancement should be logically the full development of the Certified category but to reach this objective the two other inferior categories, Open and Certified, should be fully operationally developed to demonstrate to the policy maker, regulators and the whole society that the RPAS is, in all aspects, safe enough to allows the certified RPAS operations.

Reasonably, NitroFirex stands in the second group of RPAS that operate under the rules of the Specific category. But the airspace required by the project is in fact minimal: A segregated airspace 
over of the fire would be used for an LA flying at an altitude no more of 6.000 feet over the forest fire zone and a distance of 6 to $10 \mathrm{NM}$ in respect to the intended drop zone. The LA will launch the AGCs that would need no more than 90 seconds with their filled tanks, and finally no more than an hour of navigation at an altitude of 500 feet between the fire and the mission base (the LA operating base), with the fly programmed by non populated areas to, ensure just in case any abnormal situation, a secure and soft landing.

What manned aircraft could be flying at night in the proposed zone? That is to say a zone at an altitude of 500 feet or less between a fire and the LA's mission base? It is for this very reason that a night-time operation is proposed, so that the regulations established could serve as a stepping stone for future operational regulations for RPAS in a civilian environment that need more flight time and airspace for manoeuvres.

Understanding the flight envelope proposed, and in context with the Specific regulatory authority, the profile of the AGCs recovery as proposed by NitroFirex should be the first to be regulated because the operational hours and the airspace required can not affect manned traffic. This would serve the use of RPAS in a safe and secure manner within the civilian environment of Specific category. At the same time, it may take advantage of using it as a 'launching pad' for future regular of Certified category operations in the upper layers of airspace where safety requirement and coordination are far superior owing to the altitudes and flight times needed for RPAS operations.

In one word, if in a Specific operation the low altitude profile, as proposed by NitroFirex, is not regulated and it will be extremely difficult to regulate futures Certified profiles requiring higher altitudes and longer time spans where will be flying manned aircrafts.

\section{The Aeronautical Industry and RPAS}

In the emerging and promising world of RPAS, aeronautical businesses as well as different governments and organizations are vying for good places in this race for the civil \& military market of the future that the "unmanned aviation" of air vehicles can provide. The aeronautical industry and official organizations will participate in this race with different products and business initiatives.

So, at the present moment, a differential option for the RPAS industry is to resort to ecological projects and appeal for social and political support to be able to support its participation in the development of the emergent world of unmanned aerial vehicles. The expensive, more complex and capable Certified projects must wait for better times, when the Specific category will be fully operational developed. Regarding past circumstances and now facing actual circumstances, the approach should be to find low cost projects operating in 'marginal airspace' with the purpose of keeping the regulatory bodies to a minimum.

In addition to, and taking into account present circumstances, it should be the responsibility of the organizations and businesses involved in the development of the RPAS's to refer to the economic losses, the political concern and the social fear that wild-fires generate, in order to obtain economic aid and above all political aid that a project of this nature needs for its development.

Given its relatively simple technique and minimum requirements when compared to the other RPAS projects, the NitroFirex project can and should be dealt with solely aeronautical industry, instead of having to resort to complex and problematical international alliances. In these difficult times this would allow companies to find a niche in the complex and competitive world of unmanned aerial vehicles, serving at the same time as a launching pad for the aeronautical industry to find a good position within the RPAS world by the time the civil employment of these vehicles becomes standard.

As a confirmation of the viability of the operational concept patented by NitroFirex, you can see the following video link:

https://www.dropbox.com/s/5r89j1lc9u3mwkz/VIDEO\%20COMPARTIVO-2\%20copia.mp4?dl=0 . 
This video is made with the key sequences of the NitroFirex video and the videos published, by Airbus (https://youtu.be/qCL1e1MJtSw) and by DARPA (https://www.youtube.com/watch?v=df_CjHECws).

As you can see AIRBUS, with its Future Air Power program, and DARPA in its Gremlins program, assigned to be developed by Boeing and General Atomics, are both developing the operational concept patented by Nitrofirex but only for military applications.

Then what we claim is: if the NitroFirex patent concept can be developed for military purposes by Airbus, Boeing and General Atomics, why can't it be developed for this very real and very necessary civilian application as is the night aerial forest fire fighting?

Finally should be consider by the aeronautical companies that the nocturnal extinction of forest fires is a completely virgin worldwide market niche and widely demanded by experts in fire fighting as well as by policy makers all around the world so the first company that takes positions with respect to this market will be the leader of all the rest.

With the support European Space Agency (ESA) our company NF Advanced Engineering is building MicroFirex a small NitroFirex concept demonstrator able to drop around 60 litters that will be commercialized at the end of the year.

This multi-mission modular vehicle will demonstrate NitroFirex's viability. Our next step is developing a pre-commercial concept demonstrator to be in the range of one to two thousand litters dropping capability.

NitroFirex project has been presented in different national and international fairs and great interest was shown amongst the official organizations as well as private businesses in this sector, especially regarding the exclusive and original approach on the operative and technical levels of the project.

The NitroFirex concept is patented in those countries which have an economic and aeronautic capacity to face this type of project and who also have serious wildfire problems such as the USA, Canada, Australia, the Russian Federation and Europe (Spain, France, Italy, Germany and England).

\section{Conclusions}

It doesn't make sense that, well into the XXI century, at a time when ecology in all its aspects (climate change, $\mathrm{CO}_{2}$ emissions, deforestation, etc.) becomes a red hot topic on the political, social and economic levels, we've not bothered to integrate these demands in order to combat forest fires by night.

We should assume that we are using obsolete weapons against every day stronger enemy and we are losing the battle. The big fires, the destructive ones are those that last one-day, one night and at next morning are out of control, that because we believe that the priority should be to develop the first night aerial operational capability and this is the Nitrofirex's main objective.

Or we integrate modern available technologies to develop this operational capability and be able of discharge more quantity of extinguish agent in less time over de forest fire during first night and make it at safer and cheaper way than actual aerial means or our forest will burn away irretrievably.

The use of an autonomously guided glider container, such as the one proposed in the NitroFirex project, allows for nocturnal aerial fire fighting operations, eliminates risks for crews and increases the accuracy and concentration of the releases. Besides all this, the amount of water dropped both per operating hour and per flight hour is increased with respect to the aerial methods currently used.

In addition, the launcher aircraft to be used are medium/large helicopters or military transport airlifters that are not single-role and they will continue performing operations for the rest of the year once the summer forest fire season is over. This will help bring down to a great extent the final flighthour cost (considering acquisition amortization in addition to maintenance, personnel, etc.) for the part of operations performed on fire fighting, and ultimately the cost of each dispatched litter. 
The new technologies have already been developed, matured and made available. It is only necessary to integrate them towards the objective that concerns and worries us. It is therefore up to the politicians and technicians in charge of the operation to accept the seriousness of the problem and to raise a new strategy against the ecological damage, the economic loss and the social alarm that forest fires produce.

Of course we know that our approach is ambitious, but we also know that every day is more necessary and it is technically fully available. It is high time for the managerial and academic worlds to take on the challenge that an $R \& D$ project of this nature and relevance imposes. The challenge consists in daring to develop this technological integration here and now with political decision, academicals support, managerial initiative and technological drive. 